\title{
Experimental validation of specificity of the squamous cell carcinoma antigen-immunoglobulin M (SCCA-IgM) assay in patients with cirrhosis
}

\author{
Jessica Zuin ${ }^{1}$, Gianluca Veggiani' ${ }^{1}$, Paolo Pengo ${ }^{1}$, \\ Andrea Gallotta ${ }^{1}$, Alessandra Biasiolo ${ }^{2}$, Natascia \\ Tono $^{3}$, Angelo Gatta ${ }^{2}$, Patrizia Pontisso ${ }^{2}$, Radovan \\ Toth $^{4}$, Dean Cerin ${ }^{4}$, Vladimir Frecer ${ }^{4}$, Sabrina Meo ${ }^{5}$, \\ Massimo Gion" ${ }^{6}$, Giorgio Fassina ${ }^{1}$ and Luca \\ Beneduce $^{1, *}$ \\ ${ }^{1}$ Xeptagen SpA, Marghera, Venice, Italy \\ ${ }^{2}$ Department of Clinical and Experimental Medicine, \\ University of Padua, Padua, Italy \\ ${ }^{3}$ Istituto Oncologico Veneto - I.O.V. (IRCCS), Padua, Italy \\ ${ }^{4}$ Laboratory of Molecular, Biostructural and Nanomaterial \\ Modeling, Consorzio per l'AREA di Ricerca Scientifica e \\ Tecnologica di Trieste, AREA Science Park, Trieste, Italy \\ ${ }^{5}$ ABO Association, Center for the Study of Biological \\ Markers of Malignancy, AULSS12, Venice, Italy \\ ${ }^{6}$ Center for the Study of Biological Markers of \\ Malignancy, AULSS12, Venice, Italy
}

\begin{abstract}
Background: Squamous cell carcinoma antigen-immunoglobulin M (SCCA-IgM) is a useful biomarker for the risk of development of hepatocellular carcinoma (HCC) in patients with cirrhosis due to its progressive increase associated to HCC evolution. In patients with cirrhosis, other assays have been affected by interfering reactivities of IgM. In this study, the analytical specificity of the SCCA-IgM assay was assessed by evaluating SCCA-IgM measurement dependence on different capture phases, and by measuring the recovery of SCCA-IgM reactivity following serum fractionation.

Methods: Serum samples from 82 patients with cirrhosis were analyzed. SCCA-IgM was measured using the reference test (Hepa-IC, Xeptagen, Italy) that is based on rabbit oligoclonal anti-squamous cell carcinoma antigen (SCCA) and a dedicated ELISA with a mouse monoclonal anti-SCCA as the capture antibody.
\end{abstract}

Results: SCCA-IgM concentrations measured with the reference assay (median value $=87 \mathrm{AU} / \mathrm{mL}$ ) were higher than those measured with the mouse monoclonal test (median value $=78 \mathrm{AU} / \mathrm{mL}$ ). However, the differences in the SCCAIgM distribution were not statistically significant ( $\mathrm{p}>0.05)$. When SCCA-IgM concentrations measured with both tests were compared, a linear correlation was found $(r=0.77$,

*Corresponding author: Luca Beneduce, PhD, XEPTAGEN S.p.A., Via delle Industrie 9, 30175 Marghera Venice, Italy Phone: +39041 5093910, Fax: + 390415093884 , E-mail: beneduce@xeptagen.com

Received September 22, 2009; accepted October 11, 2009; previously published online December 10, 2009 $\mathrm{p}<0.05)$. Fractionation of the most reactive sera by gel-filtration chromatography showed that total recovery of SCCAIgM reactivity was seen only in the fractions corresponding to components with a molecular weight higher than IgM and SCCA $(>2000 \mathrm{kDa})$ with both tests.

Conclusions: The equivalence of both SCCA-IgM assays and the absence of reactivity not related to immune complexes support the analytical specificity of SCCA-IgM measurements. The results validate the assessment of SCCA-IgM for prognostic purposes in patients with cirrhosis.

Clin Chem Lab Med 2010;48:217-23.

Keywords: autoantibodies; cancer biomarker; cell carcinoma antigen-immunoglobulin M; diagnostic assay; hepatocellular carcinoma; immune complexes; immunesurveillance; natural IgM.

\section{Introduction}

Tumour growth may trigger an immunogenic response that may eliminate malignant cells before they become clinically evident. When malignant cells develop a mechanism to escape the selective pressure of the immune system, the neoplasm becomes free to continue growing. Other than the elimination and escape phase, the cancer immunoediting model which is an updated and refined cancer immunesurveillance theory, predicts a temporary equilibrium state between the immune system and the tumour. In this phase, tumour growth is under the control of the immune system and continues to exert selective suppression on the transformed cells (1-5). At present, a large number of animal studies (3) and clinical observations in humans $(4,5)$ provide evidence supporting the cancer immunoediting theory. In patients with different types of cancer including liver, colorectal and prostate cancer, it is possible to detect immunoglobulin $\mathrm{M}(\mathrm{IgM})$ antibodies bound to cancer biomarkers (6-10).

It might be possible that these biomarker-IgM immune complexes are involved in cancer immunoediting, reflecting host immune protective mechanisms trying to apply selective pressure on neoplastic cells in order to combat the tumour.

In hepatocellular carcinoma (HCC) several biomarkers can be detected that are associated with IgM. The assessment of biomarker-IgM immune complexes has a higher diagnostic value compared with measurement of the free biomarker. This has been reported for $\alpha$-fetoprotein (AFP) and des- $\gamma$ carboxy-prothrombin (DCP), which are conventional serological biomarkers of HCC, and also for the newly described HCC biomarker squamous cell carcinoma antigen (SCCA) 
(7, 8). In addition, the clinical value of SCCA-IgM as a predictive biomarker of evolution of $\mathrm{HCC}$ in patients with cirrhosis has been also reported, demonstrating that the increase in serum concentrations over time of SCCA-IgM in patients with cirrhosis was associated to higher risk of development of HCC (11). The behaviour of serum concentrations of SCCA-IgM was studied in two groups of cirrhotic patients with similar clinical profiles at presentation and followed prospectively. A significant increase in serum SCCA-IgM was found only in the group of patients who developed HCC during a median follow-up of 4 years. During the same time interval, the group of patients with cirrhosis who did not progress to liver cancer had unchanged concentrations of SCCA-IgM (3). The measurement of serum SCCA-IgM could represent a helpful tool for screening patients at risk of HCC, for which conventional serological biomarkers have been shown to be ineffective (12).

Heterophilic antibodies, naturally occurring human antibodies to immunoglobulins of animal origin, or autoantibodies, could be a source of analytical interference in immunometric assays (13). Circulating endogenous IgM could bind the capture antibodies of the test and cause misleading results. Also, interference in other immunoassays by interfering IgM has also been reported (14-16). However, endogenous $\operatorname{IgM}$ interference is often undetermined in many immunoassays despite numerous reports highlighting its serious consequences (13). Interference from $\operatorname{IgM}$ depends on the nature of the antibody used in the capture phase. As a consequence different antibodies respond differently to this interference (13-16).

In this study, we assessed SCCA-IgM concentrations in patients with cirrhosis by a rabbit oligoclonal and a mouse monoclonal antibody (mAb) as capture antibodies in two different ELISA tests in order to evaluate whether the SCCAIgM assay is affected by interference from IgM. The role of IgM in measurement of SCCA-IgM was further assessed by evaluating the ability of both antibodies to recognise SCCAIgM in serum samples following removal of free $\operatorname{IgM}$ by gel filtration chromatography.

\section{Materials and methods}

\section{Patients}

Serum from 82 patients with cirrhosis [M/F ratio 3/1; mean age \pm standard deviation (SD): $56 \pm 9$ years] was collected from the Liver Unit of the Department of Clinical and Experimental Medicine, University of Padua, according to institutional approved procedures. The etiology of liver cirrhosis was alcohol abuse in 38 patients, $\mathrm{HCV}$ infection in 25 patients, HBV infection in six patients, coinfection with $\mathrm{HCV} / \mathrm{HBV}$ in six patients, and alcohol and viral infection (HBV and/or HCV) in seven patients. All patients gave fully informed consent authorising use of blood for research purpose prior to collection of samples. Patients underwent regular liver ultrasound screening to exclude the occurrence of hepatic nodules.

\section{SCCA-IgM assays}

Serum concentrations of SCCA-IgM were measured with the reference test based on a rabbit oligoclonal anti-SCCA antibody (Hepa-
IC, Xeptagen, Italy) and with an ELISA assay that used a mouse $\mathrm{mAb}$ anti-human SCCA in the capture phase to reduce interference from IgM autoantibodies. Briefly, 96-well ELISA plates were coated with $1 \mu \mathrm{g}$ of mAb anti-SCCA in $100 \mu \mathrm{L}$ of phosphate buffered saline (PBS) per well at $4{ }^{\circ} \mathrm{C}$ over night, and then blocked for $2 \mathrm{~h}$ with $1 \%$ bovine serum albumin (BSA) in PBS. After blocking, $100 \mu \mathrm{L}$ of serially diluted reference standards and samples in PBS containing $1 \%$ BSA and $0.05 \%$ Tween 20 (P-B-T) were incubated for $1 \mathrm{~h}$ at room temperature. The SCCA-IgM complex was revealed with use of peroxidase-conjugated anti-human $\operatorname{IgM}$ and developed with ABTS and hydrogen peroxidase as chromogenic substrates. The amount of SCCA-IgM complex was expressed in arbitrary units per $\mathrm{mL}(\mathrm{AU} / \mathrm{mL})$.

\section{Gel filtration}

One hundred microlitres of serum was analysed using a BioSep SEC S-4000 gel-filtration column (Phenomenex, Macclesfield, Cheshire, $\mathrm{UK})$. The elution was performed in PBS at a flow rate of $1 \mathrm{~mL} / \mathrm{min}$, and sample absorbance was monitored at $280 \mathrm{~nm}$. Serum fractions were collected every $15 \mathrm{~s}$ and immune reactivity was tested by ELISA as described above, but using $3,3^{\prime}, 5^{\prime} 5^{\prime}$-tetramethylbenzidine (TMB) as chromogenic substrate. Before the samples were loaded, a calibration run was performed according to the manufacturer's instructions.

\section{Localisation of predicted epitopes on the SCCA surface}

The antigenic epitopes of human SCCA 1 (Serpin B3) were predicted from the primary sequence of the protein (Swiss-Prot accession number P29508) using the bioinformatics server of the Cancer Vaccine Centre group of Dana-Farber Cancer Institute available at the URL http://immunax.dfci.harvard.edu/Tools/antigenic.pl. The application exploits the method of Kolaskar and Tongaonkar (17), which is based on the observation that hydrophobic amino acid residues, such as Cys, Leu and Val occurring on the surface of a protein are likely to be part of an antigenic site. Predictions are based using a table that reflects the frequency of the occurrence of individual amino acid residues in experimentally known segmental epitopes. The algorithm scans the protein sequence, calculates the residue propensity belonging to an antigenic site for a sliding window of seven residues, and calculates an average score for the whole protein. All peptides with a minimum size of eight residues that show a score above the protein average are marked as potentially antigenic. The reported accuracy of the method is $\sim 75 \%$ (17).

The three-dimensional (3D) structure of SCCA, determined by X-ray analysis (18), was obtained from Protein Data Bank (19) (PDB ID: 2ZV6). The structure of SCCA was displayed using molecular modelling software (Insight-II 2000, Accelrys, San Diego, CA, USA) and the surface area of selected residues was computed with the Connolly algorithm (20).

\section{Statistical analyses}

All analyses were performed using Analyse-it ${ }^{\circledR}$ software (Analyseit ${ }^{\circledR}$ software, Leeds, UK). Statically significant differences between the two ELISA tests for SCCA-IgM were determined with the Mann-Whitney U-test. A 2-tailed p-value of $<0.05$ was used to determine statistical significance. The Pearson product-moment correlation coefficient (PMCC) was used to calculate the linear correlation between the ELISA tests and a Bland-Altman plot was used to evaluate agreement. 


\section{Results}

A total of 82 serum samples from patients with cirrhosis were analysed for the presence of SCCA-IgM using the reference assay that employed an oligoclonal anti-human SCCA capture antibody (on the solid phase) and a test based on a mouse monoclonal anti-human SCCA antibody.

The ability of the assay that utilised monoclonal antihuman SCCA to detect SCCA-IgM immune complexes was evaluated by testing the seven calibrators of the SCCA-IgM reference assay. The calibration range of both assays was 12.5-200 AU/mL measured on a semi-logarithmic scale, and from 3.1 to $12.5 \mathrm{AU} / \mathrm{mL}$ evaluated with a linear scale.

The intra- and inter-assay variation was $5.02 \%$ and $5.14 \%$, respectively, for the test using mouse mAb anti-human SCCA as capture antibody evaluated with standard calibrators. Variability of the SCCA-IgM reference assay was $3.21 \%$ for intra-assay variation and of $1.62 \%$ for inter-assay variation.

In both assays the serum concentrations of SCCA-IgM expressed in $\mathrm{AU} / \mathrm{mL}$ were determined by interpolation of the absorbance of eight-fold diluted samples on the calibration curves plotted with SCCA-IgM calibrators.

The reproducibility of SCCA-IgM reference assay was measured using nine serum samples from cirrhotic patients, three samples with values of SCCA-IgM of 817,847 and $1523 \mathrm{AU} / \mathrm{mL}$, which fell within the upper limits of the calibration curve, three samples with values of 265,276 and $331 \mathrm{AU} / \mathrm{mL}$, which fell in the middle range of the calibration curve, and three samples with values of 121, 143 and $198 \mathrm{AU} / \mathrm{mL}$ corresponding to the bottom of the semi-logarithmic calibration range. The calculated mean values of intra-assay variation among the three samples were $9.26 \%$, $2.30 \%$ and $4.30 \%$ for serum samples falling into the top, middle and bottom range of the calibration, respectively. The mean values of inter-assay reproducibility for samples in the upper, middle and lower range of the calibration were $5.53 \%$, $3.37 \%$ and $4.60 \%$, respectively (Table 1 ).

SCCA-IgM concentrations measured with the reference assay (median value $=87 \mathrm{AU} / \mathrm{mL}$, concentration range: 48-1587 AU/mL) were higher than those measured with the

Table 1 Intra- and inter-assay coefficients of variation $(\mathrm{CV})$ for nine serum samples.

\begin{tabular}{lccl}
\hline $\begin{array}{l}\text { Sample } \\
\text { ID }\end{array}$ & $\begin{array}{l}\text { SCCA-IgM, } \\
\text { AU/mL }\end{array}$ & $\begin{array}{l}\text { Intra-assay } \\
\text { CV, } \%\end{array}$ & $\begin{array}{l}\text { Inter-assay } \\
\text { CV, } \%\end{array}$ \\
\hline 1 & 817 & 12.8 & 8.7 \\
2 & 847 & 2.1 & 2.8 \\
3 & 1523 & 12.9 & 5.1 \\
4 & 265 & 3.4 & 1.2 \\
5 & 276 & 1.7 & 2.9 \\
6 & 331 & 1.8 & 6 \\
7 & 121 & 2.5 & 7.7 \\
8 & 143 & 3.9 & 1.9 \\
9 & 198 & 6.6 & 4.2 \\
\hline
\end{tabular}

The intra-assay $\mathrm{CV}$ was determined by repeated sample analysis $(\mathrm{n}=8)$ with one assay; the inter-assay $\mathrm{CV}$ was estimated from five independent assays with samples tested in triplicate. assay using mouse $\mathrm{mAb}$ (median value $=78 \mathrm{AU} / \mathrm{mL}$, concentration range: 62-470 AU/mL) (Figure 1, Table 2). However, comparison of the two assays showed linear correlation for SCCA-IgM $(r=0.77, p<0.001$, Figure $2 \mathrm{~A})$. The distribution of serum concentrations of SCCA-IgM measured with the reference test was not different from those measured with the assay using mouse mAb (Mann-Whitney U-test two-tail $\mathrm{p}=0.3675$ ). A Bland-Altman plot was produced to show the degree of agreement between serum concentrations of SCCA-IgM measured using both methods (Figure 2B). Despite the fairly good correlation, the trend observed in the Bland-Altman plot indicates a poor relationship when serum values of SCCA-IgM are $>437.1 \mathrm{AU} / \mathrm{mL}$; the upper limit of agreement calculated as the mean difference (69.8 $\mathrm{AU} / \mathrm{mL})$ plus 1.96 SDs $(\mathrm{SD}=187.4 \mathrm{AU} / \mathrm{mL})$.

To demonstrate that the SCCA-IgM assay was not affected by interference from $\mathrm{IgM}$, we measured the recovery of SCCA-IgM reactivity following serum fractionation of the ten most reactive samples in both assays. Fractions were collected from the column every $15 \mathrm{~s}$ and tested for the presence of SCCA-IgM. Strong reactivity, corresponding to total recovery of SCCA-IgM, was obtained for both assays in the fractions eluting with high molecular weights at $6.30-7.15$ min (Figure 3). The calibration of the gel-filtration system led to the estimation of the SCCA-IgM molecular weight above $2000 \mathrm{kDa}$.

To better understand the poor relationship between the reference assay and the mouse monoclonal assay for serum values of SCCA-IgM at concentrations $>437.1 \mathrm{AU} / \mathrm{mL}$, we performed an analysis of SCCA using available structural information (18) to estimate the number of putative antigenic sites localised on the SCCA surface. The antigenic site prediction tool available at the bioinformatics server of the group of Cancer Vaccine Centre of Dana-Farber Cancer Institute returned 13 putative antigenic peptide sequences (Table 3) for the 390 residues of SCCA with an average antigenic propensity of 1.01. Among the 13 sequences, four are completely located on the surface of SCCA. Localisation of the peptide sequences on the protein surface and the area of the surface patch formed by these sequences are shown in Figure 4. To identify probable antibody binding sites among these patches, we analysed over 20 selected crystal structures of protein-Fab complexes deposited in the PDB (19). We analysed these structures in terms of average area and topology of the binding motifs recognised by Fab. The analysis showed that, in general, the Fab binding motifs on the proteins form a continuous surface patch of a roughly oval shape with flat topology and an average surface area of $550 \pm 135 \AA^{2}$, which is typically composed of residues originating from discontinuous sequences. The predicted antigenic determinants on SCCA with the largest surface area comprise the three sequences Gln51 - Asp60, Gly79 Thr90, Gly109 - Phe136 (Table 3).

\section{Discussion}

The major function of the immune system is protection from dangerous effects of the environment. Normal individuals 


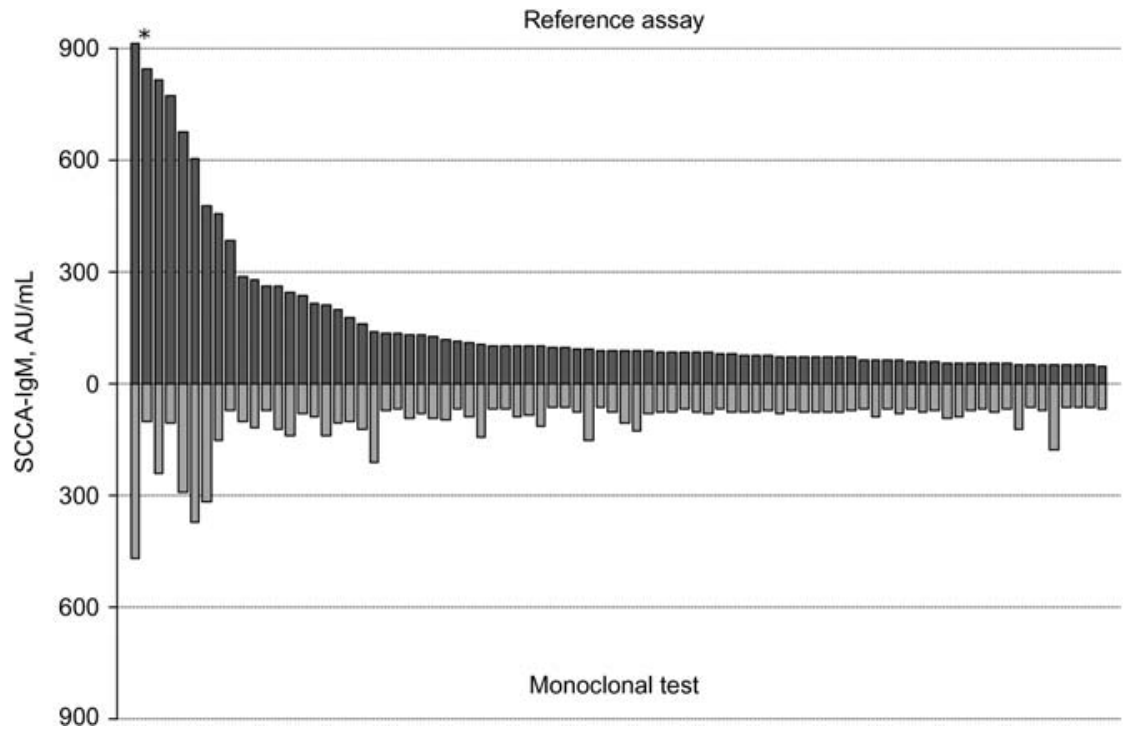

Figure 1 Distribution of SCCA-IgM serum concentrations in 82 patients with cirrhosis measured with the SCCA-IgM reference assay and with the mouse monoclonal method.

$*$ SCCA-IgM measured with reference assay $=1587 \mathrm{AU} / \mathrm{mL}$.

express various amounts of immunoglobulins in body fluids. These antibodies play an important role in induction of immune responses, representing a network of antibodies and autoantibodies that react with external non-self antigen and with self antigens, respectively $(21,22)$. Innate or natural immunity acts as the first line of defense, and also acts as the link between acquired immunity and immunological memory $(21,23)$. Polyreactive natural autoantibodies are primarily IgM that can bind with low affinity, but with high avidity, different markers of cancer growth including those with particular modifications, different glycosylation patterns, or characteristic variations in circulating concentrations in cancer-associated markers (23). Multivalent IgMs are usually considered the main component of innate immunity, with the binding capacity for a wide range of tumour markers $(24,25)$.

The occurrence of IgM immune complexes with diagnostic value has been found in different human tumours (6-10), and also in other pathologic conditions $(26,27)$.

In the case of $\mathrm{HCC}$, the diagnostic value of serum concentrations of SCCA-IgM has been demonstrated (7). Its possible role as a biomarker for risk of HCC development has

Table 2 Comparison of distribution of SCCA-IgM concentrations measured with the reference test and with the mouse monoclonal test.

\begin{tabular}{lll}
\hline Parameters & $\begin{array}{l}\text { Reference assay, } \\
\mathrm{AU} / \mathrm{mL}\end{array}$ & $\begin{array}{l}\text { Mouse monoclonal } \\
\text { test, } \mathrm{AU} / \mathrm{mL}\end{array}$ \\
\hline Means value $\pm \mathrm{SD}$ & $173 \pm 235$ & $104 \pm 69$ \\
Median value & 87 & 78 \\
Concentration range & $48-1587$ & $62-470$ \\
\hline
\end{tabular}
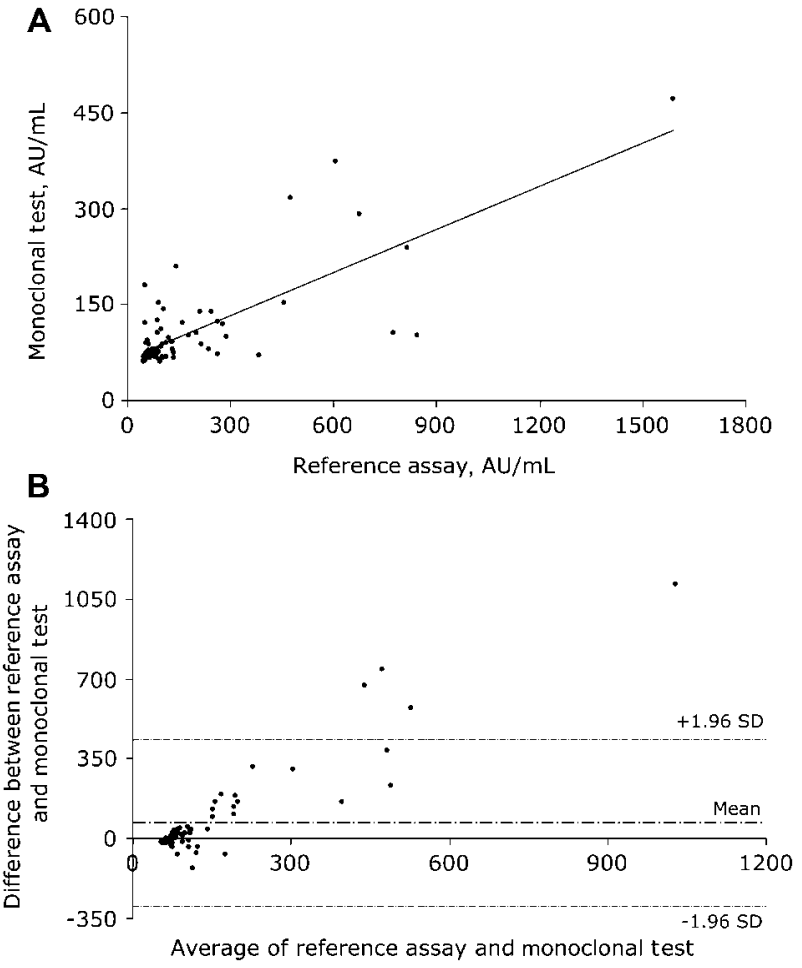

Figure 2 Comparison of serum concentrations of SCCA-IgM measured with the reference assay and with the monoclonal test. (A) Linear correlation of the distribution of SCCA-IgM concentrations measured with reference assay and monoclonal test $r=0.77$, $\mathrm{p}<0.0001$. (B) Bland-Altman difference plot for SCCA-IgM measured with both tests. The mean difference and the limits of agreement are indicated. 


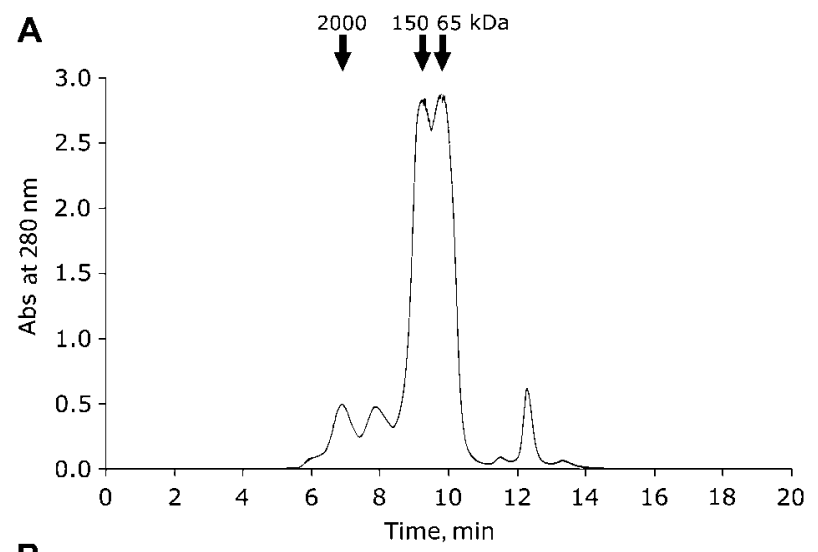

B

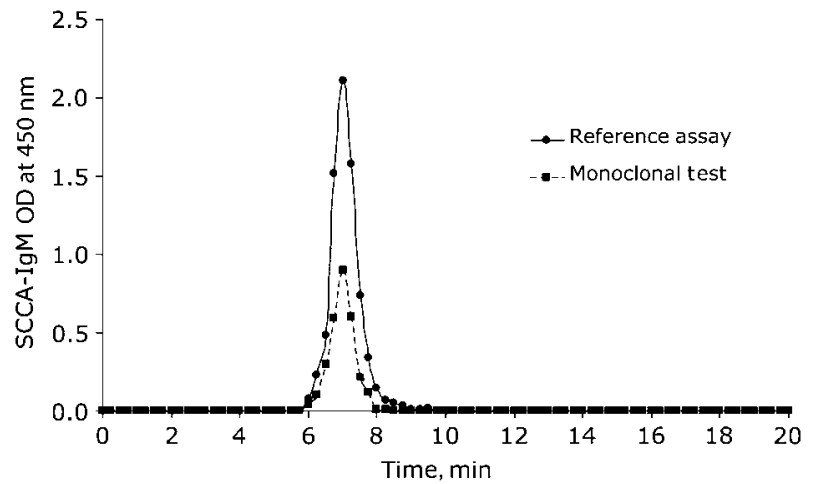

Figure 3 Serum fractionation by gel filtration chromatography. (A) Gel-filtration profile of a serum sample. (B) ELISA characterisation of collected fractions.

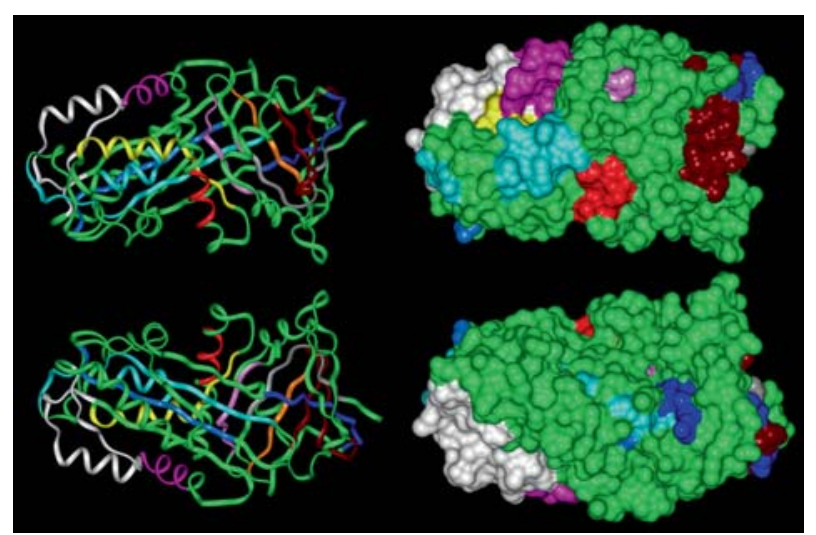

Figure 4 Ribbon representation of the backbone (left) and molecular surface (right) of SCCA, front (top) and back side (bottom) views.

For the colour coding of the sequences see Table 3.

been proposed in a prospective study of two groups of cirrhotic patients with or without HCC evolution. In this study, an increase in circulating SCCA-IgM was associated with the development of HCC (11). While conventional serum biomarkers failed in the screening of cirrhotic patients in HCC surveillance programmes, SCCA-IgM has shown promise (12). To evaluate the analytical specificity of the SCCA-IgM assay, we compared the reference ELISA assay, based upon rabbit oligoclonal antibody to human SCCA, with a dedicated immunometric test using a mAb anti-human SCCA as capture antibody.

Table 3 Predicted antigenic peptide sequences in the SCCA and their locations on the molecular surface.

\begin{tabular}{|c|c|c|c|c|c|c|}
\hline No. & Start-end & Sequence & $\begin{array}{l}\text { Peak } \\
\text { propensity }^{\mathrm{a}}\end{array}$ & $\begin{array}{l}\text { Surface } \\
\text { area }^{\text {b }}, \AA\end{array}$ & Colour ${ }^{\mathrm{c}}$ & Note \\
\hline 1 & $12-18$ & MFDLFQQ & 1.06 & 219 & Red & On surface \\
\hline 2 & $27-44$ & IFYSPISITSALGMVLLG & 1.13 & 239 & Yellow & Buried \\
\hline 3 & $51-60$ & QQIKKVLHFD $^{\mathrm{d}}$ & 1.15 & 429 & Light blue & On surface \\
\hline 4 & 79-90 & GNVHHQFQKLLT ${ }^{\mathrm{e}}$ & 1.09 & 551 & Light purple & On surface \\
\hline 5 & $109-136$ & $\begin{array}{l}\text { GEKTYLFLQEYLDAIKKFY } \\
\text { QTSVESVDF }\end{array}$ & 1.12 & 1301 & White & On surface \\
\hline 6 & $171-182$ & NTTLVLVNAIYF & 1.18 & 192 & Blue & Buried \\
\hline 7 & $216-234$ & YTSFHFASLEDVQAKVLEI & 1.13 & 730 & Brown & $\begin{array}{l}\text { Two surface patches, } \\
\text { partially buried }\end{array}$ \\
\hline 8 & $241-248$ & LSMIVLLP & 1.16 & 48 & Orange & Buried \\
\hline 9 & $278-287$ & TRVDLHLPRF & 1.12 & 234 & Dark blue & $\begin{array}{l}\text { Three surface patches, } \\
\text { partially buried }\end{array}$ \\
\hline 10 & $320-336$ & SRGLVLSGVLHKAFVEV & 1.20 & 453 & Cyan & $\begin{array}{l}\text { Several surface patches, } \\
\text { partially buried }\end{array}$ \\
\hline 11 & $342-352$ & EAAAATAVVGF & 1.14 & n.a. ${ }^{f}$ & - & Probably on surface \\
\hline 12 & $363-372$ & FHCNHPFLFF & 1.13 & 224 & Grey & $\begin{array}{l}\text { Several surface patches, } \\
\text { partially buried }\end{array}$ \\
\hline 13 & $379-386$ & NSILFYGR & 1.03 & 202 & Pink & $\begin{array}{l}\text { Several small surface } \\
\text { patches, partially buried }\end{array}$ \\
\hline
\end{tabular}

${ }^{\mathrm{a}}$ Maximum propensity score of a residue within the indicated antigenic peptide sequence. ${ }^{\mathrm{b}}$ Total molecular surface of SCCA molecule is equal to $14,472 \AA^{2}$. 'Colouring scheme, Figure 4, base colour of SCCA - light green. ${ }^{\text {d Residues }} 60-81$ are missing in the crystal structure due to poor electron density (18). ${ }^{e}$ Residues of the four largest surface patches that actually contribute to the surface area are shown in bold face. ${ }^{\mathrm{f}}$ Not available. 
In our study, the distribution of SCCA-IgM in serum from 82 patients with cirrhosis was not significantly different using both tests. However, some lack of agreement between the assays at higher SCCA-IgM concentrations was demonstrated by Bland-Altman analysis. This likely reflected the lower binding capacity of the mAb compared to the oligoclonal antibody. The recovery of SCCA-IgM reactivity following gel-filtration was tested using both assays. In both cases, the recovery of total SCCA-IgM reactivity was seen in the fractions corresponding to high molecular weight proteins only $(>2000 \mathrm{kDa})$. Since SCCA-IgM concentrations measured with the reference assay were always higher than those measured with the mouse monoclonal test, the antibody binding capacity for SCCA was investigated using an insilico analysis of putative antigenic sites.

Although experimental evidences suggest the presence of at least two distinct antigenic determinants on the SCCA surface (28), a detailed characterisation of SCCA antigenic sites is not available. The presence of two or more distinct antigenic sites on the SCCA surface with adequate size and topology for antibody recognition as predicted by in silico analysis may provide significantly different modes of binding of the SCCA-IgM immune complexes to monoclonal anti-SCCA antibodies compared to oligoclonal anti-SCCA. In fact, oligoclonal antibodies may capture SCCA-IgM immune complexes that do not bind monoclonal monospecific anti-SCCA antibody. The test with the mAb might underestimate total circulating immune complexes due to steric hindrance from the enormous mass of $\operatorname{IgM}(900 \mathrm{kDa})$ covering the SCCA surface (45 kDa) which is the binding site recognised by the $\mathrm{mAb}$. Alternatively, lack of agreement between the assays at higher SCCA-IgM concentrations could be due to binding capacity of SCCA-IgM in the mouse monoclonal test. Despite these considerations, the overall results showed good correlation for measuring SCCA-IgM concentrations.

SCCA-IgM immunoreactivity in both assays was related to the presence of the immune complexes only, and was not affected by other serum components. This supports the analytical specificity of the SCCA-IgM assay and validates its usefulness in HCC surveillance programme.

\section{Conflict of interest statement}

Authors' conflict of interest disclosure: The authors stated that there are no conflicts of interest regarding the publication of this article. Research support played no role in the study design; in the collection, analysis, and interpretation of data; in the writing of the report; or in the decision to submit the report for publication.

Research funding: This study was supported in part by FIRB project 2003, Nanosized Cancer Polymarker Biochip, project code RBLA03S4SP.

Employment or leadership: None declared.

Honorarium: None declared.

\section{References}

1. Swann BJ, Smyth MJ. Immune surveillance of tumors. J Clin Invest 2007;117:1137-45.

2. Zitvogel L, Tesniere A, Kroemer G. Cancer despite immunosurveillance: immunoselection and immunosubversion. Nat Rev Immunol 2006;10:715-27.

3. Dunn GP, Bruce AT, Ikeda H, Old LJ, Schreiber RD. Cancer immunoediting: from immunosurveillance to tumor escape. Nat Immunol 2002;3:991-8.

4. Buell JF, Gross TG, Woodle ES. Malignancy after transplantation. Transplantation 2005;80:S254-64.

5. Bhardwaj N. Harnessing the immune system to treat cancer. J Clin Invest 2007;117:1130-6.

6. Beneduce L, Castaldi F, Marino M, Tono N, Gatta A, Pontisso $\mathrm{P}$, et al. Improvement of liver cancer detection with simultaneous assessment of circulating levels of free alpha-fetoprotein (AFP) and AFP-IgM complexes. Int J Biol Markers 2004; 19:155-9.

7. Beneduce L, Castaldi F, Marino M, Quarta S, Ruvoletto M, Benvegnù L, et al. Squamous cell carcinoma antigen-immunoglobulin $\mathrm{M}$ complexes as novel biomarkers for hepatocellular carcinoma. Cancer 2005;103:2558-65.

8. Beneduce L, Pesce G, Gallotta A, Zampieri F, Biasiolo A, Tono $\mathrm{N}$, et al. Tumour-specific induction of immune complexes: DCP-IgM in hepatocellular carcinoma. Eur $\mathrm{J}$ Clin Invest 2008;38:571-7.

9. Castaldi F, Marino M, Beneduce L, Belluco C, De Marchi F, Mammano E, et al. Detection of circulating CEA-IgM complexes in early stage colorectal cancer. Int J Biol Markers 2005;20:204-8.

10. Beneduce L, Prayer-Galetti T, Giustinian AM, Gallotta A, Betto G, Pagano F, et al. Detection of prostate-specific antigen coupled to immunoglobulin $\mathrm{M}$ in prostate cancer patients. Cancer Detect Prev 2007;31:402-7.

11. Pontisso P, Quarta S, Caberlotto C, Beneduce L, Marino M, Bernardinello E, et al. Progressive increase of SCCA-IgM immune complexes in cirrhotic patients is associated with development of hepatocellular carcinoma. Int J Cancer 2006; 119:735-40.

12. Giannelli G, Antonaci S. New frontiers in biomarkers for hepatocellular carcinoma. Dig Liver Dis 2006;38:854-9.

13. Ismail AA. A radical approach is needed to eliminate interference from endogenous antibodies in immunoassays. Clin Chem 2005;51:25-6.

14. Sambol AR, Hinrichs SH, Hogrefe WR, Schweitzer BK. Performance of a commercial immunoglobulin $\mathrm{M}$ antibody capture assay using analyte-specific reagents to screen for interfering factors during a West Nile virus epidemic season in Nebraska. Clin Vaccine Immunol 2007;14:87-9.

15. Dimeski G. Interference testing. Clin Biochem Rev 2008; (Suppl 1):S43-8.

16. Bakker AJ, Mücke M. Gammopathy interference in clinical chemistry assays: mechanisms, detection and prevention. Clin Chem Lab Med 2007;45:1240-3.

17. Kolaskar AS, Tongaonkar PC. A semi-empirical method for prediction of antigenic determinants on protein antigens. FEBS Lett 1990;276:172-4.

18. Zheng B, Matoba Y, Kumagai T, Katagiri C, Hibino T, Sugiyama M. Crystal structure of SCCA1 and insight about the 
interaction with JNK1. Biochem Biophys Res Commun 2009; 380:143-7.

19. Berman HM, Westbrook J, Feng Z, Gilliland G, Bhat TN, Weissig H, et al. The Protein Data Bank. Nucleic Acids Res 2000;28:235-42.

20. Connolly ML. Analytical molecular surface calculation. J Appl Cryst 1983;16:548-58.

21. Rubin B. Natural immunity has significant impact on immune responses against cancer. Scand J Immunol 2009;69:275-90.

22. Elkon K, Casali P. Nature and functions of autoantibodies. Nat Clin Pract Rheumatol 2008;4:491-8.

23. Vollmers HP, Brändlein S. Natural antibodies and cancer. J Autoimmun 2007;29:295-302.

24. Merbl Y, Itzchak R, Vider-Shalit T, Louzoun Y, Quintana FJ, Vadai E, et al. A systems immunology approach to the hosttumor interaction: large-scale patterns of natural autoantibodies distinguish healthy and tumor-bearing mice. PLoS One 2009; 4:e6053-67.

25. Vollmers HP, Brändlein S. Natural IgM antibodies: from parias to parvenus. Histol Histopathol 2006;21:1355-66.

26. Marcello A, Wirths O, Schneider-Axmann T, Degerman-Gunnarsson M, Lannfelt L, Bayer TA. Circulating immune complexes of Abeta and IgM in plasma of patients with Alzheimer's disease. J Neural Transm 2009;116:913-20.

27. Hedegaard CJ, Krakauer M, Bendtzen K, Lund H, Sellebjerg F, Nielsen CH. T helper cell type 1 (Th1), Th2 and Th17 responses to myelin basic protein and disease activity in multiple sclerosis. Immunology 2008;125:161-9.

28. Nustad K, Dowell BL, Davis GJ, Stewart K, Nilsson O, Roijer E, et al. Characterization of monoclonal antibodies directed against squamous cell carcinoma antigens: report of the TD-10 Workshop. Tumor Biol 2004;25:69-90. 